\title{
A Note on the Clutch Size and Shape of Egg Sacs of Hynobius boulengeri from the Sobo- Katamuki Mountains, Kyushu, Japan (Urodela: Hynobiidae)
}

\section{AUTHOR(S):}

Nishikawa, Kanto; Sato, Shin'ichi; Matsui, Masafumi

\section{CITATION:}

Nishikawa, Kanto ... [et al]. A Note on the Clutch Size and Shape of Egg Sacs of Hynobius boulengeri from the Sobo-Katamuki Mountains, Kyushu, Japan (Urodela: Hynobiidae). Current Herpetology 2008, 27(1): 29-34

\section{ISSUE DATE:}

2008-06

URL:

http://hdl.handle.net/2433/216834

RIGHT:

(C) 2008 by The Herpetological Society of Japan 


\title{
A Note on the Clutch Size and Shape of Egg Sacs of Hynobius boulengeri from the Sobo-Katamuki Mountains, Kyushu, Japan (Urodela: Hynobiidae)
}

\author{
KANTo NISHIKAWA*1, SHIN'ICHI SATO ${ }^{2}$, AND MASAFUMI MATSUI ${ }^{1}$ \\ ${ }^{1}$ Graduate School of Human and Environmental Studies, Kyoto University, Yoshida \\ Nihonmatsu-cho, Sakyo-ku, Kyoto 606-8501, Japan \\ 2 1-27 Uenogaoka, Oita, Oita 870-0835, Japan
}

\begin{abstract}
We report the clutch size and egg sac morphology of Hynobius boulengeri from the Sobo-Katamuki Mountains, Kyushu. A total of 11 clutches (mean clutch size $=39.2$ ), each in a pair of egg sacs, were found in a steep, rocky stream head at about $900 \mathrm{~m}$ asl. on 6 May 2000 and 5 May 2001. The morphology of the egg sac was unique, having a string-like shape without a distinct whiptail structure at the free end. The clutch size and egg sac shape of $H$. boulengeri were most similar to those of $H$. stejnegeri, which occurs parapatrically with $\boldsymbol{H}$. boulengeri in Kyushu.
\end{abstract}

Key words: Clutch size; Egg sac; Breeding site; The Hynobius boulengeri complex; Interspecific variation

\section{INTRODUCTION}

Hynobius boulengeri has been considered to occur in the mountain regions of southern Honshu, Shikoku, and Kyushu of Japan (Sato, 1954). However, Nishikawa et al. (2005) recently found that $H$. boulengeri from Kyushu contains discrete populations from the Sobo-Katamuki Mountains, the Amakusa Islands and the Osumi Peninsula, and that they are genetically closest to $H$. stejnegeri from the Kyushu Central Mountains. Thus, Nishikawa et al. (2007) suggested that $H$. boulengeri in the current definition could be split into $H$. boulengeri sensu stricto from Honshu, $H$. hirosei (once synonymized as $H$.

* Corresponding author. Tel: +81-75-753-6848; Fax: +81-75-753-2891;

E-mail address: hynobius@zoo.zool.kyoto-u.ac.jp boulengeri by Sato [1934]) from Shikoku, and $H$. spp. from Kyushu. Nevertheless, because formal description of $H$. spp. from Kyushu is still under way, we here retain $H$. spp. from Kyushu in $H$. boulengeri sensu lato, and call the latter the $H$. boulengeri complex, together with $H$. stejnegeri.

Although many aspects of life history of this complex have been reported (Sato, 1943; Nishioka, 1964; Tamura, 1980; Gose and Hayashi, 1983; Tanabe and Okayama, 2004; Tahara and Tahara, unpublished data), little has been reported on the breeding habits of $H$. boulengeri from Kyushu for more than half a century since its discovery on the island (Sato, 1954). In the Sobo-Katamuki Mountains, it is not difficult to observe larvae of this species throughout the year because they usually overwinter, sometimes as many as three times, before metamorphosis (Nishikawa and Matsui, 
2008). In contrast, finding egg sacs is very difficult, and success at this was achieved only once in 1979 when a pair of damaged egg sacs was found (Sato, 2001).

In Hynobius, egg sac shape has been used as a useful character for species identification (Sato, 1943). As noted above, the population of $H$. boulengeri in the Sobo-Katamuki Mountains is considered to be an undescribed species (Nishikawa et al., 2007), but its breeding biology has not been well documented. Thus, we report here on the oviposition sites, clutch size, and characteristics of egg sacs of $H$. boulengeri from these mountains, and compare them with other species of the complex.

\section{MATERIALS AND METHODS}

We searched for the eggs at the heads of main streams on Mts. Sobo, Katamuki, Okue, and Oyaji of the Sobo-Katamuki Mountains (550-1100 m asl) on Kyushu. In our previous surveys, we found breeding males in streams (550 $\mathrm{m}$ asl) at night in early April. In addition, post-breeding salamanders could be dug out from under the debris at streamsides (850 $\mathrm{m}$ asl) in mid-May (Nishikawa et al., unpublished). Further, the egg sacs found in 1979 (see above) were estimated to have been laid from early to mid-May (Sato, 2001). With this information in mind, we searched between early April and early May in each year from 1997 to 2005 for egg sacs in streams where we had previously found larvae in high abundance, by turning over submerged rocks and digging in small dams formed by debris.

We recorded the environmental features of the breeding sites in each survey. When we found egg sacs, we examined the clutch size (CS) and developmental stages of eggs for each. A given egg sac was measured for ESL (maximum length of egg sac excluding whiptail structure on the free end), ESW (egg sac width at the middle portion), and WTL [length of whiptail structure (WT)] if it had at least one egg developing to the early tail bud (Stage 10 in Sato [1943]) or later stages, because the egg sac shape becomes stable and does not show further prominent changes by water absorption at or after Stage 10 (Nishikawa, unpublished data). All measurements were taken to the nearest $1 \mathrm{~mm}$ with a dial caliper.

For comparisons, clutch size and egg sac properties of $H$. boulengeri sensu stricto from the Kii Peninsula of Honshu, H. hirosei from Shikoku, and H. stejnegeri from the Kyushu Central Mountains were also examined in a similar manner.

\section{RESULTS AND DISCUSSION}

We found egg sacs in a headstream $(900 \mathrm{~m}$ asl) on the northern slope of a component of the Sobo-Katamuki Mountains (detailed locality data not given for conservation purposes). The streamsides in this region were originally dominated by a number of deciduous broadleaf trees, such as Viburnum furcatum, Symplocos coreana, Sorbus commixta, and Eleutherococcus sciadophylloides. At the time of the survey, however, the site was partly covered by artificially planted Japanese cedar trees (Cryptomeria japonica). On the ridge of the mountain around $1,000 \mathrm{~m}$ asl, Japanese beech (Fagus crenata) and bamboo bush (Sasamorpha borealis) dominated. When we found the egg sacs, Rhododendron dengronianum was in blossom.

The breeding site was surrounded by bedrock, and near the site were several waterfalls (ca 2-5 $\mathrm{m}$ in height) with much debris in the basins (Fig. 1A). While searching for the eggs, we found several breeding adults among the debris (Fig. 1B). The egg sacs were laid on the bedrock or on small stones that were buried by heavily piled debris in the basins (ca $25 \mathrm{~cm}$ under the ground) (Fig. 1C). At the same site, we also found overwintered larvae of $H$. boulengeri with black claw-like structures on the tips of the digits.

We found a total of 11 pairs of egg sacs (two pairs on 6 May 2000 at $1805 \mathrm{~h}$, when the weather was fine and air and water temperatures were $17.9 \mathrm{C}$ and $12.9 \mathrm{C}$, respectively, and nine pairs on 5 May 2001 at $1030 \mathrm{~h}$, when the weather was fine and air and water tempera- 

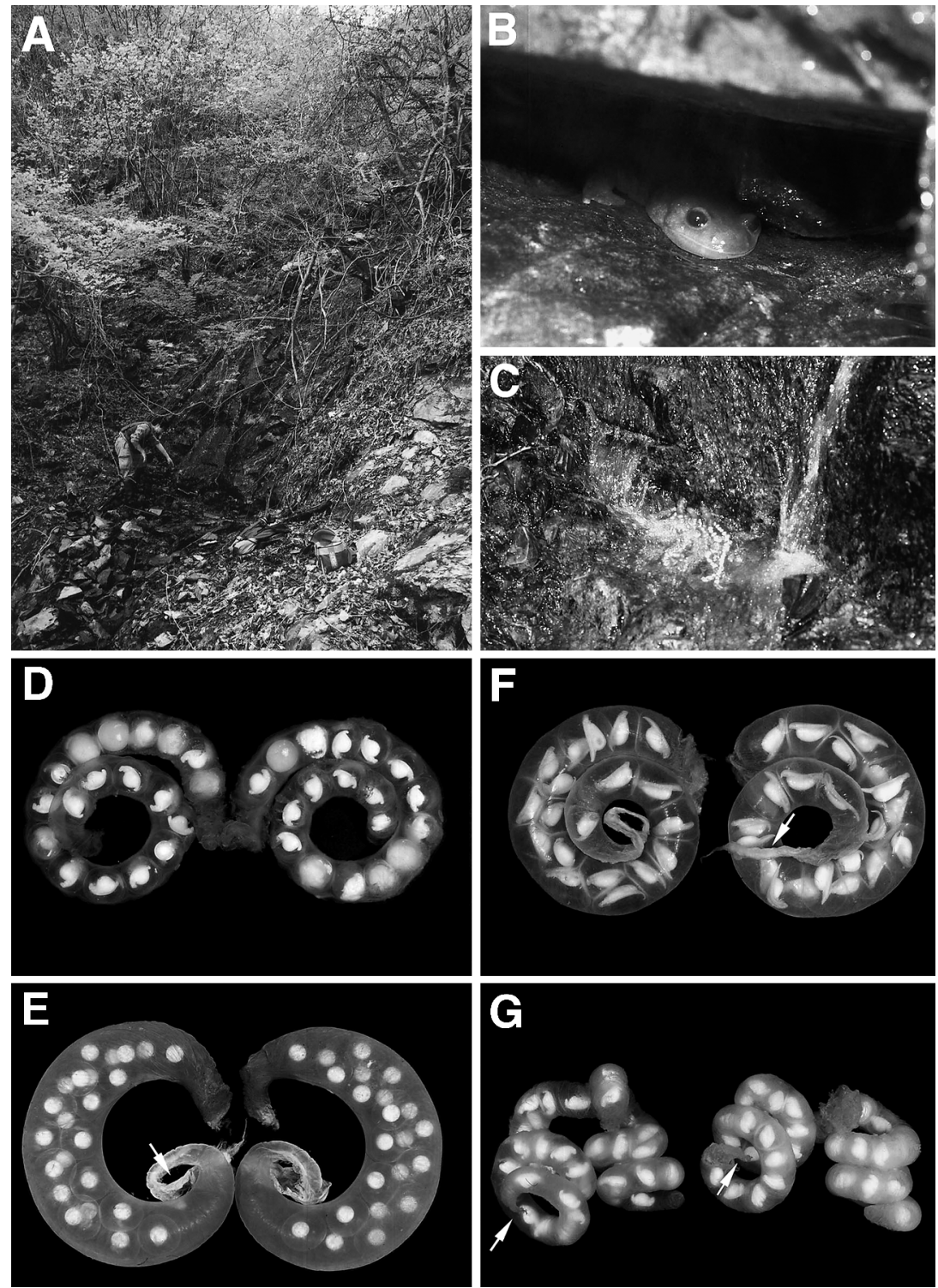

Fig. 1. A: Breeding environment. A person points to the oviposition site. B: An adult male of $H$. boulengeri from the Sobo-Katamuki Mountains, peering from a space in the debris. C: Egg sacs attached to the bedrock. D: Egg sacs of H. boulengeri from the Sobo-Katamuki Mountains. E and F: Egg sacs of $H$. boulengeri sensu stricto from the Kii Peninsula, Honshu (E) and H. hirosei from Shikoku (F). Arrows indicate whiptail structures on the free ends of the egg sacs. G: Egg sacs of $H$. boulengeri from the SoboKatamuki Mountains (left) and H. stejnegeri (right). Arrows indicate the free ends of the egg sacs.

tures were $17.2 \mathrm{C}$ and $11.2 \mathrm{C}$, respectively). The clutch size ranged from $30-57(\overline{\mathrm{x}}+\mathrm{SD}=$ $39.2 \pm 8.9)$, including $0-12$ dead eggs (3.0 \pm 3.8$)$. The egg sacs were string-like in shape (ESL ranged from $190-242 \mathrm{~mm}$ [210.8 $\pm 15.1 \mathrm{~mm}]$,
ESW from $10-15 \mathrm{~mm}[13.2 \pm 1.1 \mathrm{~mm}]$, and ESL/ESW from 13.5-23.6 [median=15.7]) and the envelope was thin. The sacs lacked a distinct whiptail structure on the free end (Fig. 1D), unlike other lotic-breeding species, 
such as $H$. boulengeri sensu stricto (Fig. 1E), H. hirosei (Fig. 1F), H. kimurae, and $H$. tsuensis (Sato, 1943). The eggs formed a single row in each egg sac.

The developmental stage of the eggs varied from the late neural plate to mid-tail bud stages (Stages 9-11 in Sato [1943]). It is known that $H$. hirosei from Shikoku breeds between early and mid-May and that the eggs take three to four weeks to hatch in water temperature of 8-9 C (Sato, 1943). Judging from these data, the eggs found at an altitude of $900 \mathrm{~m}$ asl in the Sobo-Katamuki Mountains seem to have been laid in late April and would have hatched by late May. Because we found many newly hatched larvae (Stages 58 and 59 of Iwasawa and Yamashita [1991]), which had already appeared in a stream by early May at $550 \mathrm{~m}$ asl in the same mountain range (Nishikawa and Matsui, 2008), the breeding season may be earlier at altitudes lower than that of the site where we found egg sacs.

The clutch size varies geographically but largely overlaps among the taxa of the $H$. boulengeri species complex (Table 1). The clutches of $H$. boulengeri from the SoboKatamuki Mountains $(\overline{\mathrm{x}} \pm \mathrm{SD}=39.2 \pm 8.9$, range $=$ 30-57) were larger than those of $H$. hirosei (30.3 $\pm 7.8,14-59$ : Student's t-test, $\mathrm{t}=2.41, \mathrm{df}=$ $52, \mathrm{P}=0.019$ ), but did not differ significantly from those of $H$. boulengeri sensu stricto (43.2 $\pm 11.4,19-63: \mathrm{t}=0.23, \mathrm{df}=47, \mathrm{P}=0.820)$ and $H$. stejnegeri $(36.0 \pm 8.3,21-57: \mathrm{t}=1.11$, $\mathrm{df}=42, \mathrm{P}=0.273$ ).

The egg sacs of $H$. boulengeri from the Sobo-Katamuki Mountains were longer (ESL: $210.8 \pm 15.1 \mathrm{~mm}, 190-242 \mathrm{~mm}$ ) than those of $H$. boulengeri sensu stricto $(176.8 \pm 42.8 \mathrm{~mm}$, 117-273 mm: Aspin-Welch's t-test, $\mathrm{t}=4.62$, $\mathrm{df}=56, \mathrm{P}<0.001), H$. hirosei $(177.9 \pm 58.2 \mathrm{~mm}$, 85-276 mm: $\mathrm{t}=4.14, \mathrm{df}=80, \mathrm{P}<0.001)$, and H. stejnegeri $(193.4 \pm 43.8 \mathrm{~mm}, 100-300 \mathrm{~mm}$ : $\mathrm{t}=2.32, \mathrm{df}=56, \mathrm{P}=0.024)$. In contrast, $H$. boulengeri from the Sobo-Katamuki Moun-

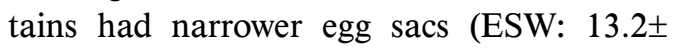
$1.1 \mathrm{~mm}, 10-15 \mathrm{~mm}$ ) than $H$. boulengeri sensu stricto (22.5 $\pm 2.7 \mathrm{~mm}, 17-28 \mathrm{~mm}$ : Aspin-Welch's t-test, $\mathrm{t}=19.60, \mathrm{df}=59, \mathrm{P}<0.001)$ and $H$. hirosei $(17.1 \pm 2.1 \mathrm{~mm}, 10-23 \mathrm{~mm}: \mathrm{t}=11.07$, $\mathrm{df}=71, \mathrm{P}<0.001)$. However, they did not significantly differ in ESW from $H$. stejnegeri $(13.8 \pm 2.5 \mathrm{~mm}, 9-20 \mathrm{~mm}: \mathrm{t}=1.23, \mathrm{df}=41, \mathrm{P}=$ 0.224 ) (Table 1). Thus, the shape of egg sacs, as expressed by ESL/ESW, in $H$. boulengeri from the Sobo-Katamuki Mountains (median= $15.7,13.5-23.6)$ was distinctly narrower than in $H$. boulengeri sensu stricto $(7.7,4.4-10.6)$ and was statistically significantly narrower than in $H$. hirosei $(9.8,4.8-17.9$ : Mann-Whitney U-test, $\mathrm{U}=112.00, \mathrm{P}<0.001)$ and $H$. stejnegeri (13.5, 8.8-19.2: $\mathrm{U}=164.00, \mathrm{P}=0.002)$ (Table 1). In summary, $H$. boulengeri from the SoboKatamuki Mountains has the longest egg sac, and its shape is narrowest among the species of the complex, while it is similar to $H$. stejnegeri in clutch size and egg sac width.

The egg sacs of $H$. boulengeri sensu stricto and $H$. hirose $i$ are banana-like and not coiled (Fig. 1E, F), and have a relatively strong envelope compared with that of $H$. boulengeri from the Sobo-Katamuki Mountains and $H$. stejnegeri. Further, the egg sacs of the former two species have a beautiful light blue hue and are equipped with a well-developed whiptail structure on the free end (Fig. 1E, F, Table 1). In contrast, the egg sac of $H$. boulengeri from the Sobo-Katamuki Mountains is characterized by a string-like shape, coiled two and a half times, a thin envelope, and a lack of any distinct whiptail structure (Fig. 1G left, Table 1). All these characteristics are similar to those seen in $H$. stejnegeri (Fig. $1 \mathrm{G}$ right, Table 1).

Based on allozymic and morphological analyses, Nishikawa et al. (2007) found the population of $H$. boulengeri from the SoboKatamuki Mountains to be distinct enough for recognition as a species distinct from $H$. boulengeri sensu stricto and $H$. hirosei. As shown here, the egg sac characteristics also support such a taxonomic idea. Similarly, close resemblance in breeding characteristics of $H$. boulengeri from the Sobo-Katamuki Mountains with $H$. stejnegeri also agrees with their sister relationship as estimated by the allozymic and morphological studies (Nishikawa et al., 2007). 


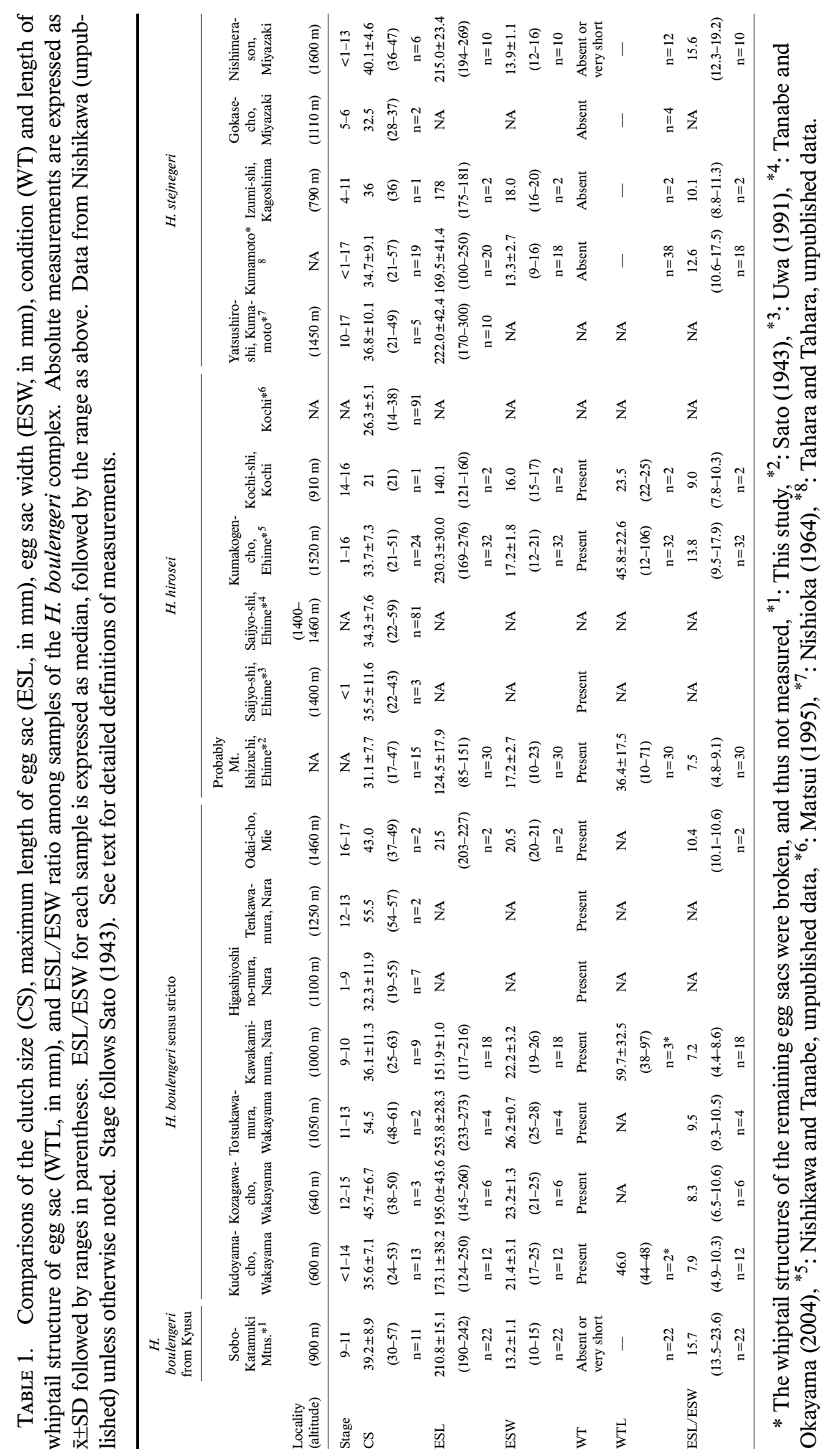


Unfortunately, neither breeding sites nor egg sacs have been found for $H$. boulengeri on the Amakusa Islands and the Osumi Peninsula. In order to fully understand variations in clutch size and egg sac shape of the $H$. boulengeri complex, surveys are needed for these populations.

\section{ACKNOWLEDGEMENTS}

We thank Mr. T. Shimada for his help in digitalizing the photographs, Mr. S. Tanabe for introducing literature, Mr. T. Sueyoshi for providing literature, and Mr. T. Hadano for his suggestions on description of flora around the sampling site. We are also grateful to Mr. T. Johnson for linguistic advice. This study was partly supported by grants from the Showa Seitoku Memorial Foundation and the Fujiwara Natural History Foundation to the senior author.

\section{LITERATURE CITED}

Gose, K. and Hayashi, Y. 1983. Ecology and conservation of Hynobius boulengeri. Iden 37: 57-61. (in Japanese)

Iwasawa, H. AND Yamashita, K. 1991. Normal stages of development of a hynobiid salamander, Hynobius nigrescens Stejneger. Japanese Journal of Herpetology 14: 39-62.

Matsui, M. 1995. Hynobius boulengeri. p. 410415. In: Japan Fisheries Agency (ed.), Basic Data for Endangered Wild Aquatic Organisms of Japan (II). Japan Fisheries Resource Conservation Association, Tokyo. (in Japanese)

Nishikawa, K. AND Matsui, M. 2008. A comparative study on the larval life history in two populations of Hynobius boulengeri from Kyushu, Japan (Amphibia: Urodela). Current Herpetology 27: 9-22.

Nishikawa, K., Matsui, M., and Tanabe, S. 2005.
Biochemical phylogenetics and historical biogeography of Hynobius boulengeri and H. stejnegeri (Amphibia: Caudata) from the Kyushu region, Japan. Herpetologica 61: 54-62.

Nishikawa, K., Matsui, M., Tanabe, S., and SATo, S. 2007. Morphological and allozymic variation in Hynobius boulengeri and $H$. stejnegeri (Amphibia: Urodela: Hynobiidae). Zoological Science 24: 752-766.

NishioKa, T. 1964. A note on finding the egg sac of Hynobius stejnegeri. Saisyu-to-Shiiku 26: 361363. (in Japanese)

SATO, I. 1934. Studies on salamanders from Shikoku. I. On the salamanders found at Ishizuchiyama and its vicinity. Zoological Magazine, Tokyo 46: 464-472.

SATo, I. 1943. A Monograph of the Tailed Batrachians of Japan. Nippon Shuppan-sha, Osaka. (in Japanese)

Sato, S. 1954. On Pachypalaminus boulengeri Thompson from Kyushu. Zoological Magazine, Tokyo 63: 195-199. (in Japanese)

Sato, S. 2001. From my old field notes (1) The first encounter with Hynobius boulengeri (Caudata: Hynobiidae) Kyusyu. Bulletin of the Herpetological Society of Japan 2001: 8-11. (in Japanese)

TAmURA, T. 1980. Yamanoko to Sanshouo [Mountain Children and Salamander]. GakushuKenkyu-sha, Tokyo. (in Japanese)

Tanabe, S. And OKayama, T. 2004. Clutch size of the salamander, Hynobius boulengeri in the Mt. Ibuki, Ehime Prefecture. Bulletin of Omogo Mountain Museum (1): 9-11. (in Japanese)

UwA, T. 1991. On the development of Hynobius boulengeri. Bulletin of the Education and Research of Matsuyama-Higashi High School, Ehime Prefecture 24: 46-56. (in Japanese)

Accepted: 25 March 2008 